\title{
IMPLEMENTING EFFICIENT AND EFFECTIVE LEARNERSHIPS IN THE CONSTRUCTION INDUSTRY
}

\author{
Authors: \\ Claudia Mummenthey \\ Ronel du Preez ${ }^{1}$
}

\section{Affiliations:}

${ }^{1}$ Department of Industrial Psychology, Stellenbosch University, South Africa

\section{Correspondence to:}

Ronel du Preez

email:

rdp@sun.ac.za

\section{Postal address:}

Department of Industrial Psychology, Private Bag X1, Matieland, Stellenbosch University, South Africa

\section{Keywords:}

CETA; construction industry; learnerships; skills development;

learnership system

\section{Dates:}

Received: 12 Nov. 2008 Accepted: 09 July 2010 Published: 09 Nov. 2010

How to cite this article: Mummenthey, C., \& du Preez, R. (2010). Implementing efficient and effective learnerships in the construction industry. SA Journal of Industrial Psychology/SA Tydskrif vir Bedryfsielkunde, 36(1), Art. \#766, 11 pages. DOI: 10.4102/sajip.v36i1.766

This article is available at: http://www.sajip.co.za

(C) 2010. The Authors. Licensee: OpenJournals Publishing. This work is licensed under the Creative Commons Attribution License.

\section{ABSTRACT}

Orientation: Overcoming skills deficits has been a major concern in South Africa since the advent of democracy in 1994.

Research purpose: This study investigated the current state of the learnership system in the construction sector and identified the major obstacles.

Motivation for the study: The study was an attempt to illustrate why it is necessary to implement efficient and effective learnerships in the construction industry

Research design, approach and method: A learnership evaluation framework was developed and indicated the critical factors for efficient and effective learnership implementation as well as the roles of the various key stakeholders. The sample included respondents from building and civil companies $(n=90)$, learners $(n=135)$, accredited training providers $(n=14)$ and Construction Education and Training Authority and industry-related bodies $(n=10)$.

Main findings: It was found that descriptive statistics, non-parametric tests and a content analysis of the Western Cape data indicated that, despite low satisfaction with the system in the workplace and among institutional providers, the learnership system was nevertheless regarded as an appropriate means to develop artisans.

Practical/managerial implications: Companies were motivated to offer learnerships but felt inadequately prepared for actual implementation. Learnerships were felt to demonstrate effectiveness in terms of employability and skills enhancement.

Contribution/value-add: This research provides a theoretical framework to understand, describe and assess the implementation of efficient and effective learnerships in the construction industry.

\section{INTRODUCTION}

Overcoming skills deficits has been a major concern in South Africa since the advent of democracy in 1994. To this end, the learnership system, which was established by the Skills Development Act, Act No. 97 of 1998 (effectively in place since 2000), proposes a dual vocational-training model (theoretical learning at a training institution with practical on-the-job-training in the workplace) resulting in a recognised national occupational qualification. To enrol in a learnership, a candidate has to be contracted to an employer (De Jager et al., 2002; Heitmann, 2004); the system therefore generates employment, while simultaneously developing the skills base of a learner according to labour-market needs. To ensure growth and quality in the system, the Sector Education and Training Authorities (SETAs) have been given the responsibility of overseeing and promoting skills development in general and learnership training in particular in their own economic sectors (Republic of South Africa [RSA], 1998). The SETA with responsibility for the construction industry is the Construction Education and Training Authority (CETA). Financial incentives for employers to invest in learnership training are regulated by the Skills Development Levies Act, Act No. 9 of 1999 (RSA, 1999).

Since its inception, however, and even though it features in the top 10 learning interventions of the most recent South African training industry report (Meyer \& Bushney, 2007, p. 37), the system has not met expectations, particularly in terms of employer participation. This is especially true for the construction sector, which is labour intensive (with 700000 employees and being the largest contributor to current GDP growth), uses relatively elementary skills and is regarded as one of the key drivers for reducing unemployment and poverty. This sector also provides infrastructure to support economic growth in all other economic sectors (CETA, 2007a; CIDB, 2004; Goldmann, 2003; Nankani, 2006; Stats SA, 2008a).

Despite its pivotal role in creating the country's future, the latest available submission rates of the workplace skills plans (WSP) (indicating participation in the learnership system) reveal that participation in the sector is very low, with only 1443 enterprises out of 23979 levy-paying enterprises (in other words 6\%) submitting WSP (CETA, 2007a). The level of participation in learnership training is also low, even though the industry faces severe skills constraints, particularly in carrying out the government's Accelerated Shared Growth Initiative for South Africa (AsgiSA), which has allocated R372 billion to a massive infrastructure programme for the provision of general infrastructure and in preparation of the 2010 FIFA World Cup (CIDB, 2006b, 2007a; Thejane, 2007). There is furthermore strong consensus that the rising demand for construction is outpacing the supply of appropriately trained and qualified people at all levels (CIDB, 2007a, 2007b). Indeed, according to the latest quarterly analysis of the Bureau of Economic Research (BER, 2008, p. 17), no fewer than $98 \%$ of building contractors struggle to obtain the required number of skilled people. As the learnership system is regarded as one of the major means for 
developing artisan skills in the industry (CETA, 2007a; CIDB, $2007 \mathrm{~b}$ ), it is therefore imperative that the efficient and effective implementation of the system in the industry be addressed urgently.

The overall objective of this study is therefore to investigate the current state of the learnership system in the construction industry and to identify critical factors for its efficient and effective implementation. Specific objectives include the following:

1. Investigate the general satisfaction level of the various stakeholders with the learnership system and determine the appropriateness of the system.

2. Investigate the competence levels of the learnership providers in providing learnerships.

3. Identify the primary process needs of the stakeholders.

4. Determine the effectiveness of the system with regard to the development of applied competence and to future employability or to further education opportunities for the learners.

For this purpose, the key stakeholders of the learnership system in the construction industry needed to be identified. As defined by Aspinwall, Simkins, Wilkinson and McAuley (1992, p. 84) $\therefore$. . a stakeholder is any group or individual who is affected by or [who] can affect the future of a programme or activity'. The following key stakeholders were accordingly identified: CETA (with its constituting stakeholder bodies); building and civil employers and their representative industry associations; construction learners and accredited training providers.

Figure 1 graphically represents the developed framework on major relationships and on interactions among the stakeholders as well as the influencing factors for an effective learnership system in the construction industry. The framework gives recognition to the complexity of the relationships among the multiple stakeholders, the flow of resources and finances, formal transactions, actual training as well as required cooperation among bodies and therefore makes the dynamics of the system that are relevant to efficient and effective implementation transparent and accessible.

A learnership evaluation framework (Figure 2) was subsequently developed for this study based on an in-depth analysis of national and sector challenges for learnership implementation (such as low education levels, the emigration of skilled labour, HIV/Aids, the nature of work and employment practices in the sector as well as the image of the sector) and on a review of relevant evaluation literature.

The evaluation framework (Figure 2) follows the systems approach for training. The thinking underlying a systems approach is that, firstly, any functioning entity can be viewed as a system and can be defined in terms of what it is attempting to achieve (the outcome). Secondly, every system can be broken down into sub-systems and into the interrelationships among them (Erasmus \& van Dyk, 1996; Patrick, 1992). The two main constituting components of a system are considered inputs and outputs (Edney, 1972). To avoid 'black-box phenomena' (no attention paid to what is happening between inputs and outputs, the actual processing remaining a 'black box'), focus on these needs to be extended to processes (Madaus, Airasian \& Kellaghan, 1980). A systems evaluation therefore focuses on the whole system and the relationships among the interdependent components or sub-systems (input, process and output) forming the system (Bramley, 1991). As suggested by Nielsen and Visser (1997, p. 14), in the context of vocational education,

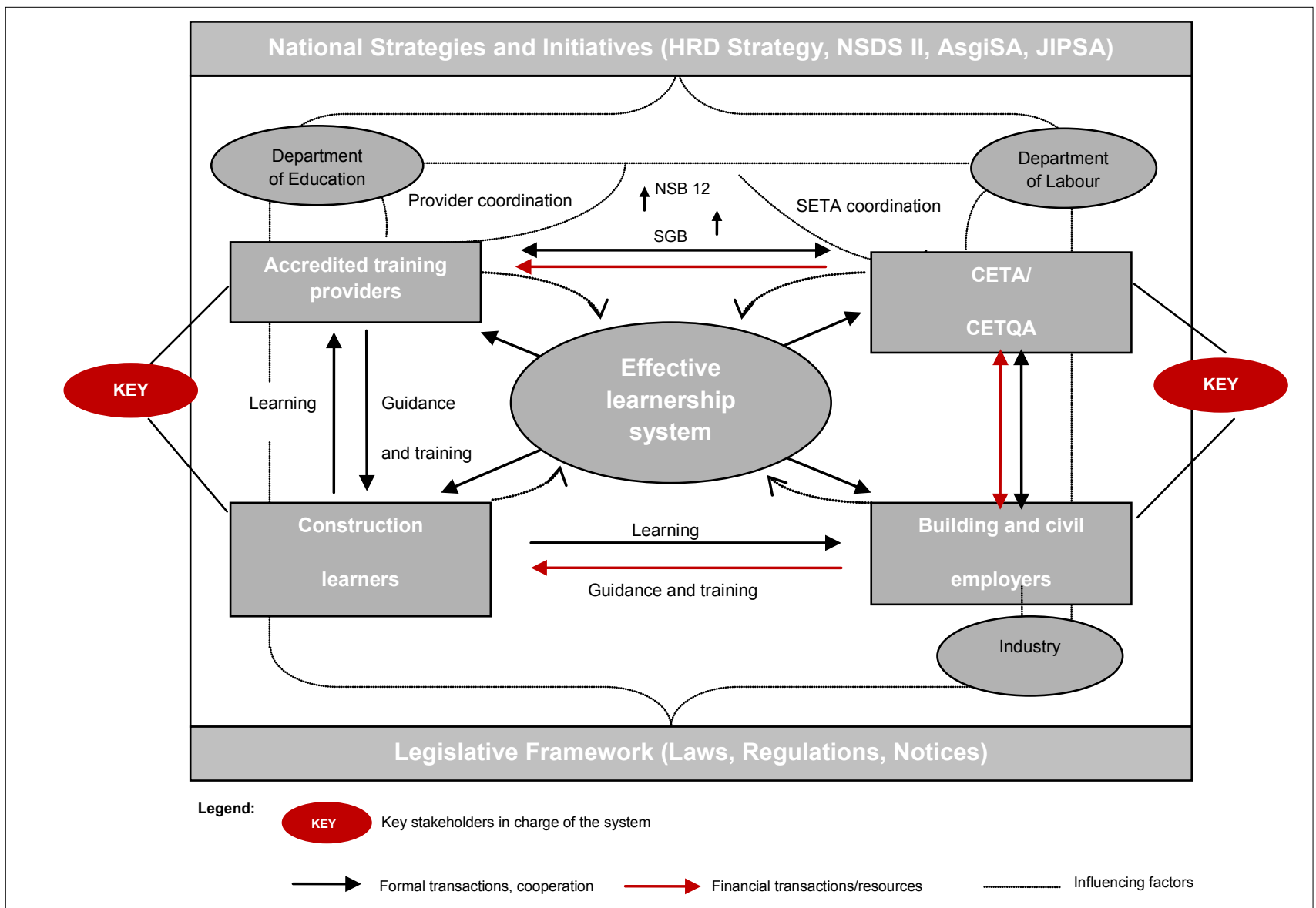

Source: Mummenthey, C. (2008). *Implementing efficient and effective learnerships in the construction industry. A study on the learnership system in the building and civil sector of the Wester Cape, p. 23. Unpublished master's thesis, Stellenbosch University, South Africa. 


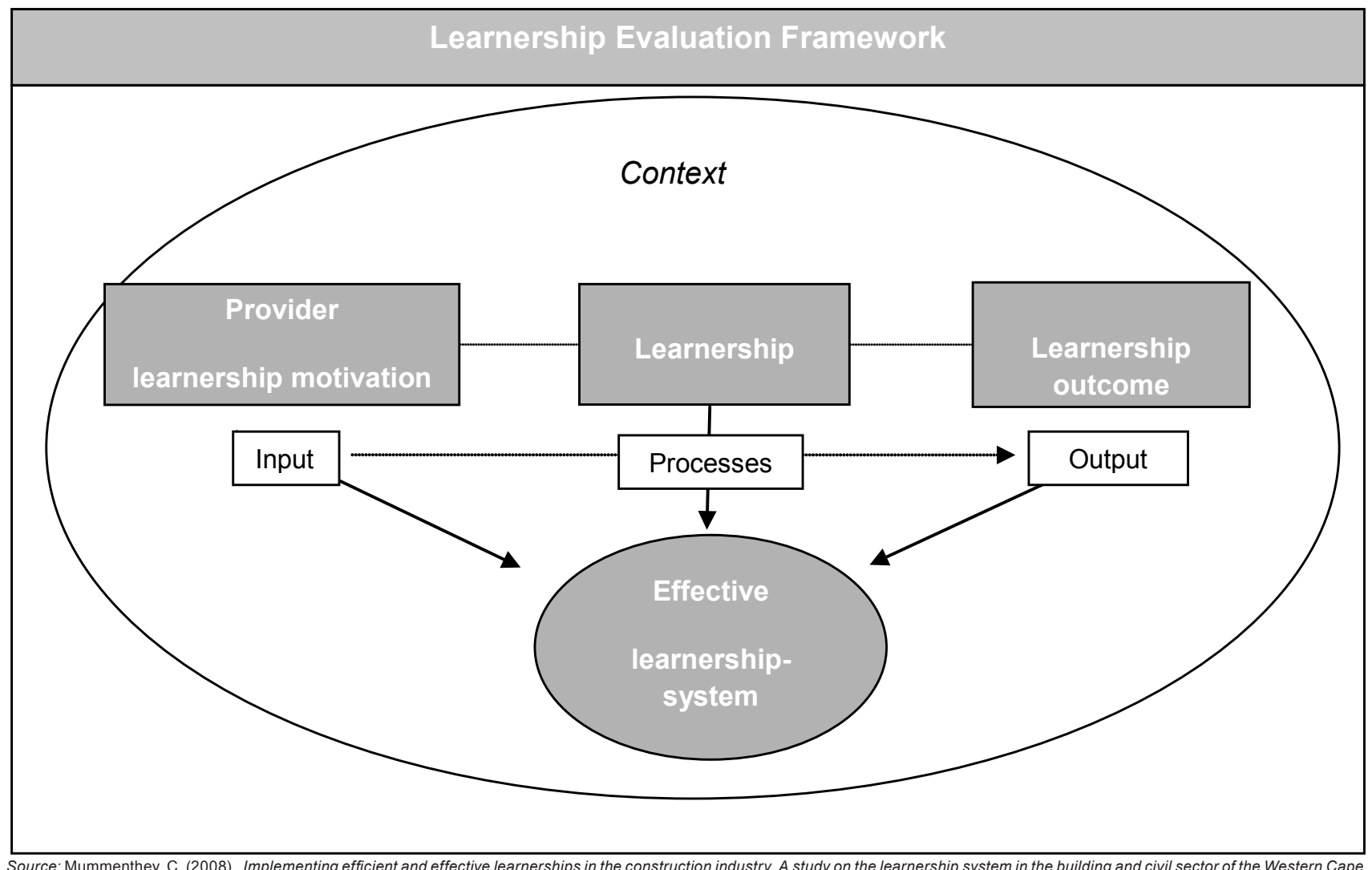
Source: Mummenthey, C. (2008). Implementing efficient and effective learnershi
p. 68. Unpublished master's thesis, Stellenbosch University, South Africa.

the achievement of quality objectives should be tested on four dimensions: (1) Input: For example the qualifications and motivations of those involved and the resources provided by the training institutions; (2) Process: For example the aim, structure and content of the course, the planning and execution of teaching, the physical framework and the teachers; (3) Product: For example course completion, passed examinations and school-leaver competences and (4) Effect: For example employment, productivity and competitiveness. The model therefore includes these dimensions.

Although several research publications on learnerships and their implementation exist (Babb, 2004; Babb \& Meyer, 2005; Berger \& Douglas, 2004; Davies \& Farquharson, 2004; Fester, 2006; Smith, Jennings \& Solanki, 2005; Wolhuter, 2003), this is the first overall post-implementation study involving all the stakeholders of a sector and, importantly, attempts to evaluate both the efficiency and the effectiveness of the system in terms of its outcomes from a human-resources management perspective. This first comprehensive evaluation of the system is therefore significant not only for the construction industry but also from a more general perspective, in other words as an important contribution to what is considered to be a scarce research and knowledge area in South Africa (Davies \& Farquharson, 2004; Smith et al., 2005). It is anticipated that this study will provide a base model for future ongoing evaluations of the implementation of the learnership system. The research was conducted with general support from the CETA. The Employment and Skills Development Service programme of German-Technical Cooperation, in partnership with the Department of Labour, supported the research both technically and financially within the framework of the South African-German Development Cooperation, which is funded by the German Federal Ministry of Economic Cooperation and Development.

\section{RESEARCH DESIGN}

\section{Research approach}

An ex post facto mixed-methods research design was employed in this study. Both quantitative and qualitative methods (in other words mixed methods), namely a survey research (a web and telephone survey) and key-informant interviews, were used. Ex post facto research takes the world as given and studies effects after they have occurred (Punch, 1998. As Kerlinger and Lee [2000, p. 558] define, '. . . non-experimental research is systematic empirical inquiry in which the scientist does not have direct control of independent variables because their manifestations have already occurred'. By blending qualitative and quantitative methods, it is possible to benefit from the strength of one method while offsetting its weaknesses through the other method [Rubin \& Babbie, 2007]). Given the nature of the research and the fact that the learnership system was implemented in 2001, this approach was the most valuable and appropriate.

\section{Research method}

\section{Research participants}

To ensure the representivity of all the major stakeholders involved in the system, a detailed examination was conducted and appropriate samples (considering the given context of this study, the available research resources and the set time frame) of each stakeholder population were drawn. Refer to Table 1.

Building and civil companies: Sampling and data collection in the company web survey relied on resources that could provide existing email contacts for building and civil companies active in the Western Cape. These were the following:

- CETA

- the Construction Industry Development Board (CIDB) 
TABLE 1

Respondent characteristics - Western Cape

\begin{tabular}{|c|c|c|}
\hline Stakeholder group & Respondent characteristics & Survey medium \\
\hline $\begin{array}{l}\text { Building/Civil companies } \\
\text { Large, medium, small/micro-sized }\end{array}$ & $\begin{array}{l}N=90 \text { building/civil companies: } \\
\text { Involvement in learnerships: } \\
\text { - } 54 \% \text { not yet involved } \\
\text { - } 46 \% \text { involved } \\
\text { Company size: } \\
\text { - Small: } 63 \% \quad(1-49 \text { employees }) \\
\text { - Medium: } 22 \% \quad(50-149 \text { employees }) \\
\text { - } \quad \text { Large: } 15 \% \quad(>=150 \text { employees })\end{array}$ & Web survey \\
\hline Construction learners (completed learnership in 2006) & $\begin{array}{l}N=135 \text { construction learners } \\
\text { 18.1/18.2 learners: } 56 \% \text { (18.1), } 44 \% \text { (18.2) } \\
\text { NQF level: } 59 \% \text { (NQF 1), 19\% (NQF 2), 22\% (NQF } 3-5) \\
\text { Gender: } 79 \% \text { male, } 21 \% \text { female } \\
\text { Age: } 53 \%(35+), 37 \%(25-34), 10 \%(15-24) \\
\text { Ethnic group: } 79 \% \text { coloured, } 18 \% \text { African, } 1 \% \text { white, } 2 \% \text { Indian/Asian }\end{array}$ & Phone interviews \\
\hline Accredited training providers & 14 representatives from 9 different accredited construction training providers & Personal interviews/ e-mail \\
\hline Various representative associations and CETA & $\begin{array}{l}10 \text { key informants from the following organisations: } \\
\text { BCC, BWAWUSA, CIDB, CETA, Department of Public Works, MBA, SAFCEC }\end{array}$ & Personal interviews/ e-mail \\
\hline
\end{tabular}

- the Master Builders Association (MBA)

- the South African Federation of Civil Engineering Contractors (SAFCEC)

- $\quad$ specific websites for the construction industry.

The existing databases led to a sample frame of $n=729$ building and civil companies to be contacted. Due to the different underlying definitions of the categories (small/micro, medium and large) made in the databases used, a distinction of this sample into small/micro, medium and large businesses could not be made. For the 588 companies contacted, the contact details proved to be correct. A sample of $n=90$ (a 15\% response rate) resulted.

As displayed in Table 1, most of the respondents in the building and civil-company sample were small companies with 1 to 49 employees (63\%), followed by medium companies with 50 to 150 employees (22\%). Accordingly, $85 \%$ of the responding companies belonged to the small, micro to medium-sized business (SMME) sector. Only 15\% of the responding companies had more than 150 employees. While $54 \%$ of the respondents indicated to be registered with the CETA, only the minority $(46 \%)$ stated to be actively involved in learnership training. The respondent characteristics, particularly regarding company size and involvement in learnerships, demonstrated high consistency with the general industry characteristics, namely a dominance of SMMEs, comprising between $80 \%$ and $97 \%$ of the sector (CETA, 2007a; Ntinga, 2002) and low involvement in learnerships (CETA, 2007a).

Construction learners: The learner population consisted of a cluster of 766 learners who completed their construction learnerships in the Western Cape throughout 2006. The time period after the completion of the learnerships was long enough to enable the learners to use their acquired knowledge and skills and to see how well they had been prepared for their jobs; the time period was also short enough for the learners still to remember what their training had consisted of (Campbell, 1998). The time period was selected to ensure that the respondents could reflect on the entire process of their learnerships and could make statements with regard to their employability or further training opportunities after completion of their learnerships. A sample of $n=135$ (a 23\% response rate) resulted.

The majority of the learners were over 25 years of age $(90 \%)$, with a large proportion being 35 years and older (53\%); only $10 \%$ of the learners were in the age group of between 15 and 24 years. The majority of the learners were trained at NQF level 1 (59\%), only $19 \%$ of the learners being registered at NQF level 2 and $22 \%$ at NQF levels 3 to 5 . Given the current state of the construction industry (an already ageing workforce) and the fact that the industry is experiencing a major artisan backlog (at NQF levels 3 to 4), training ratios in terms of younger learners and higher NQF levels will certainly have to be increased (CIDB, 2004) if the system is to meet the industry's needs.

Accredited training providers: The sample frame for the accredited training-provider group consisted of the five major training providers active in providing formal construction training in the Western Cape. The opinions of various staff members of these institutions (regional managers or managing directors, heads of department, training coordinators or managers and instructors) were included. Additional input from other accredited training providers (from other provinces) was obtained during the data-collection process, which increased the sample size to $n=14$.

CETA and industry-related associations and bodies: To obtain the view of CETA, a sample of three key staff members was drawn $(n=3)$. From the representative associations, the sample included seven key informant interviews $(n=7)$ from the following most influential institutions:

- the Black Construction Council (BCC)

- MBA

- SAFCEC

- Building, Wood and Allied Workers' Union of South Africa (BWAWUSA)

- Construction Industry Development Board (CIDB)

- the Department of Public Works (Western Cape).

\section{Measuring instrument}

In the absence of an existing measurement instrument, a questionnaire was developed for the purpose of this study. The instrument was based on the research questions and the established evaluation framework as well as on supplementary expert interviews used to verify content and to identify additional areas of concern in the major sections. 
Four questionnaires were designed for the various stakeholder groups, (1) for companies, (2) for construction learners, (3) for the accredited training providers and (4) for CETA and the industry-related associations and bodies. All the questionnaires followed the same design, with some variation in questions (according to stakeholder needs) to make cross-checks and comparisons possible. Pilot studies and expert verification in all the stakeholder groups were used to confirm content and the face validity of the questionnaires. Inter-rater reliability was used in both the quantitative analysis and the qualitative analysis (comparing the consistency of the ratings among the different stakeholder groups). Besides its recognised role in quantitative research, this is also a well-accepted method to address reliability in qualitative research (Creswell, 2007).

The questionnaire consisted of six main sections:

- Section 1: Learnership satisfaction and the appropriateness of the learnership system (4 items).

- Section 2: Provider-learnership competence (10 items).

- Section 3: Learnership processes (12 items).

- Section 4: Provider-learnership motivation (4 items).

- Section 5: Learnership outcome (7 items).

- Section 6: Statistical data, skill constraints and open comments (13 items).

Section 1: Learnership satisfaction and the appropriateness of the learnership system (4 items): Two sub-sections were included, namely general satisfaction with the system (e.g. 'how satisfied are you with the newly established learnership system with regards to your industry?') (extremely satisfied [1] to not at all satisfied [5]) and the perceived appropriateness of the system (e.g. 'do you regard learnerships as an appropriate means to develop artisans for the construction industry?') (definitely [1] to definitely not [5]). Each sub-section further included an opportunity for qualitative comments by the respondents.

Section 2: Provider-learnership competence (10 items): Provider-learnership competence was measured with specific reference to technical competence (e.g. professional knowledge/ expertise to train the profession), methodological competence (e.g. innovative [action-oriented and outcome-based] training methods) and interpersonal competence (e.g. guiding and mentoring the learner) on a five-point Likert scale, ranging from 1 ('extremely well prepared') to 5 ('not at all prepared').

Section 3: Learnership processes (12 items): Learnership processes (e.g. availability of information on the learnership process and its benefits, support given by CETA and WSP submission process) that are important for an efficient and effective learnership system were included in this section. The five-point Likerttype intensity scale used in this section ranged from excellent 1 ('excellent') to 5 ('poor'). Open space was provided for general comments.

Section 4: Provider-learnership motivation (4 items): The respondents indicated their current motivation to get or stay involved in the system (extremely high [1] to no interest at all [5]). Motivations for the choices were given by the respondents with the use of multiple-selection alternatives (five items) and space to cite other reasons, if necessary. This section is not reported on in this paper.

Section 5: Learnership outcome (7 items): Learnership outcome measured the work readiness or employability as well as the further training opportunities of the learners who completed the learnership programme. For the learner group, this section recorded the current employment and income status of the respondents. Items measuring the learners' opinion on whether the learnership had improved their chances of employment, of higher income or of a promotion were included and responses were given, ranging from 1 ('definitely') to 5 ('definitely not'). In the other stakeholder groups, learnership outcome was measured according to technical, methodological and interpersonal competence.
Section 6: Statistical data, skill constraints and open comments (13 items): This section recorded respondent demographic data, depending on the stakeholder group. The learner questionnaire recorded general educational level, company size, the type of learnership (18.1/18.2), the NQF level of the learnership and general information on age, gender and ethnic group. For the other groups, this section included sample characteristics, such as training history and activity, company size and current position in the organisation. Again space was provided for open comments.

\section{Research procedure}

As the various stakeholder groups required different research procedures, these are discussed separately.

Building and civil companies Building on the established company-questionnaire design, a web platform was programmed by a specialised web designer. Programming was done with particular focus on simplicity and user-friendliness in design, as this was acknowledged to be significant for response (Dillmann, Tortora, Conradt \& Bowker, 1998; Van Selm \& Jankowski, 2006); entry to the web questionnaire was secured by a general username and password. The respondents were invited via email to complete the questionnaire on the platform. After several reminders and a time frame of fiveand-a-half weeks, a sample of $n=90$ was obtained, which is a response rate of $15 \%$. The data were automatically stored in a separate database.

Construction learners The entire list of learners with a completed learnership in 2006 (as retrieved from the CETA database) was phoned without further selection procedures over a three-month period. The interviews were conducted both in English and in Afrikaans, depending on the preferred language indicated by the respondents. A large number of learners could not be reached but those who were reached all agreed to be interviewed, representing a response rate of $22 \%$.

Accredited training providers Personal interviews were conducted with the providers $(n=14)$. Email or telephonic contact was made with the interviewees and the purpose of this study was explained. No major difficulties were encountered and all the providers invested one to two hours to give detailed input, which was recorded on the questionnaire. Two respondents could not be interviewed in the time frame of six weeks and elected to contribute by responding electronically to the questions.

CETA and industry-related associations and bodies Data in this category were relatively difficult to collect due to incorrect contact details and the restricted availability of the contacted informants. Several follow-up calls had to be made and reminders had to be sent to obtain a personal interview with all the key informants $(n=10)$.

All interview data were recorded on the questionnaires in paper format and then transferred into an excel-file template. The transfer of the data between the two media was doublechecked for each respondent to ensure that no data distortion occurred in the process due to typing errors.

\section{Statistical analysis}

Data were analysed using the Statistica 8 program (StatSoft, Inc., Tulsa, OK) for the quantitative data and using content analysis for the qualitative data. The main quantitative analysis applied within this study was descriptive statistics. Non-parametric tests were performed for independent group comparisons, which were applied to the building and civil-company as well as the learner samples.

\section{RESULTS}

For reasons of consistency and ease of comparison, the findings across all the groups were provided in percentages, despite the fairly small size of the samples of the accredited training 
provider as well as CETA, and the industry-related associations and bodies groups. The responses of the key informants from CETA and the other industry-related organisations were deliberately summarised within one group to preserve the anonymity of the respondents. The discussion of the results follows the sequence of the previously stated research objectives.

\section{Learnership satisfaction - Research objective 1}

One of the first and central research questions to be answered was whether the stakeholders were generally satisfied with the current learnership system. As reflected in Table 2, the providers and key informants (the workplace and institutions) demonstrated high dissatisfaction with the learnership system. In addition, almost a quarter (21\%) of the workplace providers (building and civil companies) were not aware of or informed about the system to the extent that they could express either satisfaction or dissatisfaction with it. Moreover, the majority of the non-responding participants indicated not having had any personal experience with the system. This high lack of knowledge about learnerships and what they entail in terms of implementation became more transparent throughout this study. Exemplary comments in this context were the following:

- We have very little info as to the modus operandi of this system.

- I am not fully aware of the learnership system.

Only the construction learners and consequently the primary beneficiaries of the learnership expressed a considerable level of satisfaction (89\%) with the system.

\section{Reasons for dissatisfaction}

The most prominent reasons given for the dissatisfaction expressed were the following:

\section{Building and civil companies:}

- The availability of and access to information about the learnership system.

- The CETA services and processes (support and administration, formal procedures and bureaucracy, funding and finances).

- The availability of industry-suitable learnerships with adequate learnership content.

- The quality of learnership outc omes.

\section{Accredited training providers:}

- The CETA services and processes, particularly funding, formal procedures and bureaucracy.

- The unsuitability of the learnership content (not or no longer industry-suitable).

- The availability and lack of information about the system.

\section{Learners:}

- Non-completion: Due to financial controversies between the training provider and CETA.

- Certification: Delay in the processing of certificates (some learners had been waiting for their certificates for over six months).

A total of $18 \%$ of the learners in the survey had not completed their learnerships, the main reason being that CETA had not paid the formal training provider (hence the financial controversies) and the training could therefore not be completed. Not being able to complete their learnerships and not yet having received their certificates were perceived by the respondents as the greatest impediments to employability.

\section{Reasons for satisfaction}

The main reasons for satisfaction with the system across all the stakeholder groups were the following:

- The opportunity of skills enhancement and empowerment

- The practical applicability of the training.

- The quality and structure of the training (the holistic, integrated approach combining both theory and practice).

The learners, in particular, appreciated having had the opportunity to enhance their skills, this being expressed with statements such as 'learned more about construction than ever before, learnership was very good' and 'looking forward to doing second level'.

The overall satisfaction of the learnership providers and the practical knowledge of the building and civil companies about the learnerships were very low. The National Skills Survey (NSS) on very small and micro enterprises (VSME), of which the findings were reported by McGrath and Martins (2005), found broadly similar respondent percentages of 'no comment' in connection with the learnership services offered by the SETAs. According to these findings, at least one out of four respondents (25\%) was not able to comment on the majority of the services due to not having received such services (McGrath \& Martins, 2005 , p. 48). A tremendous lack of awareness and not being recipients of such services were therefore the most common aggregate reason for the non-response among the NSS survey participants. Those who did comment on the offered services tended to be negative, with at least $30 \%$ of the respondents being not at all satisfied (McGrath \& Paterson, 2007, p. 348).

\section{Appropriateness of the learnership system - research objective 1}

The large majority of the respondents regarded the system as an appropriate means for developing artisans (Table 3). Noteworthy is that a large proportion of the building and civil respondents $(21 \%)$ who could not indicate either satisfaction or dissatisfaction with the system did have a clear opinion on the general appropriateness of the system (non-response was 3\%); their opinions were largely positive.

The respondents' views on the system were the following

- It is vital to have a structured course for each and every trade forming the basis and setting a required standard for learners to be measured before being able to join the industry.

- In times where skills are seriously lacking, hands on training is a sure way to skill the labourers.

- Implemented correctly from A-Z it should work.

Strong evidence existed that the current criticism on the learnership system was not fundamental but was concerned rather with issues of practical implementation and the set-up of processes, most importantly the availability of information about the system. This finding was consistent with the findings of two previous qualitative studies on the learnership system (Babb, 2004; Fester, 2006). Both studies revealed that, even

TABLE 2

Learnership satisfaction - across all groups

\begin{tabular}{|c|c|c|c|c|c|c|}
\hline \multirow[b]{2}{*}{ Respondent group } & \multicolumn{5}{|c|}{ Satisfied } & \multirow{2}{*}{$\begin{array}{l}\text { Don't knowl } \\
\text { No response }\end{array}$} \\
\hline & Extremely & Very & Normal & Not very & Not at all & \\
\hline Building/Civil companies & $3 \%(n=3)$ & $4 \%(n=4)$ & $18 \%(n=16)$ & $30 \%(n=27)$ & $23 \%(n=21)$ & $21 \%(n=19)$ \\
\hline Construction learners & $20 \%(n=26)$ & $30 \%(n=39)$ & $39 \%(n=51)$ & $10 \%(n=14)$ & $1 \%(n=2)$ & $0 \%(n=0)$ \\
\hline Accredited training providers & $7 \%(n=1)$ & $7 \%(n=1)$ & $21 \%(n=3)$ & $50 \%(n=7)$ & $14 \%(n=2)$ & $0 \%(n=0)$ \\
\hline CETA, industry-related asso-ciations/bodies & $0 \%(n=0)$ & $30 \%(n=3)$ & $10 \%(n=1)$ & $50 \%(n=5)$ & $10 \%(n=1)$ & $0 \%(n=0)$ \\
\hline
\end{tabular}


TABLE 3

Appropriateness of the learnership system - across all groups

\begin{tabular}{|c|c|c|c|c|c|c|}
\hline \multirow[b]{2}{*}{ Respondent group } & \multicolumn{5}{|c|}{ Appropriateness } & \multirow{2}{*}{$\begin{array}{l}\text { Don't know/ } \\
\text { no response }\end{array}$} \\
\hline & Definitely & Probably & Fairly likely & Probably not & Definitely not & \\
\hline Building/Civil companies & $51 \%(n=46)$ & $21 \%(n=19)$ & $14 \%(n=13)$ & $4 \%(n=4)$ & $6 \%(n=5)$ & $3 \%(n=3)$ \\
\hline Accredited training providers & $57 \%(n=8)$ & $7 \%(n=1)$ & $14 \%(n=2)$ & $14 \%(n=2)$ & $7 \%(n=1)$ & $0 \%(n=0)$ \\
\hline CETA, industry-related associations/bodies & $50 \%(n=5)$ & $30 \%(n=3)$ & $0 \%(n=0)$ & $10 \%(n=2)$ & $10 \%(n=1)$ & $0 \%(n=0)$ \\
\hline
\end{tabular}

among those participants who expressed dissatisfaction with their particular learnership experiences, there remained a positive sentiment towards the learnership system in general.

\section{Provider-learnership competence - research objective 2}

Unsurprisingly, the accredited training providers demonstrated strong confidence in being prepared for learnership training (it was their core business and all the formal training providers had been involved in training for more than four years). The majority $-55 \%$ - of the building and civil companies indicated that they felt well prepared and $33 \%$ indicated that they were prepared (Table 4). However, $41 \%$ indicated that they felt not very well or not at all prepared; further support is therefore needed.

An overwhelming majority of the providers indicated that they required support (the building and civil companies: 90\%; the accredited training providers: $79 \%$ ). The respondents (over $60 \%$ of both companies and providers) indicated that such support should be provided by CETA, followed by the CIDB and the representative industry organisations (such as SAFCEC, MBA and the National Home Builders Registration Council). This strongly suggested that the providers, despite their dissatisfaction with CETA, still regarded it as the main provider of learnership services but expected much more than was being delivered. The following areas of support emerged:

\section{Building and civil companies:}

- Practical guidance on starting, operating and managing learnership training (emphasising the lack of general and practical knowledge).

- General information about the system.

- Support in dealing with occurring problems during training (such as discipline, learning problems and HIVI Aids).

\section{Accredited training providers:}

- The provision of training and learning material (the development of training material, and learner, assessor and practitioner guides).

- Support in dealing with occurring problems during training.

These results provided further evidence to Fester (2006) and Kruss (2004), who found that there was generally a poor grasp, awareness and understanding of the new education and training policy. This included, in particular, what learnerships were, what they entailed in terms of implementation and what was needed to implement them successfully.

\section{Learnership processes - research objective 3}

The respondents were asked to rate a range of 12 processes connected to the actual implementation of the learnerships. The results of this section (across all the providers) painted a highly negative picture of the respondents' perceptions of the learnership processes. Almost all the processes were rated by the majority of the respondents in the categories of either fair or poor. The most criticised processes, which emerged from the quantitative analysis and were confirmed by the open comments of the respondents on the processes, were the following:

- support given by CETA

- the availability of information about the system

- the financing scheme of the system and the formal procedures (in other words bureaucracy).

Accordingly, the civil and building companies perceived the lack of support, particularly in terms of clear information about and practical guidance on the system as well as the financing scheme (funding) and the highly bureaucratic formal procedures, as the major procedural challenge to an efficient and effective learnership system.

The respondents illustrated this opinion with the following comments:

- More information and assistance with finance, recruitment, training and development.

- Bureaucratic rompslomp; if a company does not have a dedicated HR department the process is cumbersome; too much paper work and not enough support for small companies to manage the admin.

- Just in general, the whole process needs to be put in a format more 'user-friendly'.

Contrary to the providers, the learners demonstrated high levels of satisfaction in terms of the processes directly affecting them during their training, such as the quality of support and guidance by the employers and training provider (viewed as excellent) as well as the availability of suitable learning material. The only process that was rated by the majority of the learners $(52 \%)$ as fair or poor was that of assessment and certification due to the delay in the processing of the certificates.

The finding that the processes in connection with CETA were perceived as unsatisfactory and therefore regarded as a general constraint was consistent with two previous studies: the NSS 2003 on VSME, which similarly reported low levels of satisfaction with SETA services (McGrath \& Paterson, 2007) and the 2007 report on the South African skills crisis (CDE, 2007). From the 40 surveyed companies from different sectors, 19 companies were negative about SETAs, mainly because they found dealing with SETAs to be cumbersome.

\begin{tabular}{|c|c|c|c|c|c|c|}
\hline \multirow[b]{2}{*}{ Respondent group } & \multicolumn{5}{|c|}{ Prepared } & \multirow{2}{*}{$\begin{array}{l}\text { Don't know/ } \\
\text { no response }\end{array}$} \\
\hline & Extremely well & Very well & Prepared & Not very well & Not at all & \\
\hline Building/Civil companies & $9 \%(n=8)$ & $13 \%(n=12)$ & $33 \%(n=30)$ & $33 \%(n=30)$ & $7 \%(n=6)$ & $4 \%(n=4)$ \\
\hline Accredited training providers & $21 \%(n=3)$ & $57 \%(n=8)$ & $21 \%(n=3)$ & $0 \%(n=0)$ & $0 \%(n=0)$ & $0 \%(n=0)$ \\
\hline CETA, industry-related associations/bodies & $0 \%(n=0)$ & $20 \%(n=2)$ & $30 \%(n=30)$ & $50 \%(n=30)$ & $0 \%(n=0)$ & $0 \%(n=0)$ \\
\hline
\end{tabular}


TABLE 5

Learnership outcome (overall competence/work readiness) - Across all groups

\begin{tabular}{|c|c|c|c|c|c|c|}
\hline \multirow[b]{2}{*}{ Respondent group } & \multicolumn{5}{|c|}{ Outcome } & \multirow{2}{*}{$\begin{array}{l}\text { Don't know/ } \\
\text { no response }\end{array}$} \\
\hline & Excellent & Very good & Good & Fair & Poor & \\
\hline Building/Civil companies & $0 \%(n=0)$ & $6 \%(n=5)$ & $20 \%(n=18)$ & $26 \%(n=23)$ & $11 \%(n=10)$ & $38 \%(n=34)$ \\
\hline Accredited training providers & $0 \%(n=0)$ & $21 \%(n=3)$ & $36 \%(n=5)$ & $43 \%(n=6)$ & $0 \%(n=0)$ & $0 \%(n=0)$ \\
\hline \multirow[t]{3}{*}{ CETA, industry-related associations/bodies } & $0 \%(n=0)$ & $0 \%(n=0)$ & $50 \%(n=5)$ & $40 \%(n=4)$ & $10 \%(n=1)$ & $0 \%(n=0)$ \\
\hline & \multicolumn{5}{|c|}{ Prepared } & \\
\hline & Extremely well & Very well & Normal & Not very well & Not at all & $\begin{array}{l}\text { Don't know/ } \\
\text { no response }\end{array}$ \\
\hline Construction learners & $14 \%(n=18)$ & $47 \%(n=62)$ & $24 \%(n=31)$ & $10 \%(n=13)$ & $0 \%(n=0)$ & $5 \%(n=7)$ \\
\hline
\end{tabular}

\section{Learnership outcome - research objective 4}

To evaluate the effectiveness of the system with regard to the development of applied competence and the future employability of the learners, the last research objective was concerned with actual learnership outcome. The training providers indicated that the learnership system did not yet deliver a high level of applied competence (or work readiness). Consistent with the overall findings, a large proportion of the building and civil companies could not respond to this statement, as they had not experienced the system (38\%; Table $5)$, with others indicating 'fair' or 'poor' for the outcome in terms of applied competence. The majority of the accredited training providers $(57 \%)$ rated the applied competence level between 'very good' and 'good', of which the larger part (36\%) rated it 'good'. Only the learners demonstrated high confidence in feeling 'extremely well prepared' (14\%), 'very well prepared' $(47 \%)$ and 'prepared' $(24 \%)$

The stakeholder groups agreed that, to develop competent artisans, the duration of training had to be at least 24 months and required a balanced split between practical and theoretical training. Particularly the learners requested more practical training. In addition, the majority of the stakeholders emphasised that the learnership content needed to be revised according to the latest industry needs and requirements.

Despite the low ratings with regard to applied competence, the system has nevertheless been effective in terms of employability; all the groups demonstrated employability rates of over $80 \%$. Of the learners themselves, $61 \%$ indicated that they were employed in the construction industry. Of the remaining 39\%, 43\% were employed in another profession, leading to an overall learner employment rate of $76 \%$. The majority of the learners $(51 \%)$ held the view that, after completing their learnerships, their chances for employment were 'definitely' higher than before. Nearly $45 \%$ of the learners were convinced that their learnerships had 'definitely' improved their chances of higher income and promotion. Almost a quarter (24\%) said that this was 'probably' the case. Even though this result may, in part, be affected by the current need for skills in the industry, this is a significantly positive result in terms of the actual impact of the system.

Differences in learner groups: An analysis was performed to determine whether differences occurred with regard to the employability of the learners based on the type of learners (18.1 learners had been previously employed and $18.2 \mathrm{had}$ been previously unemployed), on whether the learners had completed their learnerships, on employment status during the learnerships and on NQF level. Table 6 indicates the significant results. Accordingly, 18.1 learners had a significantly higher chance of employment after completing their learnerships than 18.2 learners. This resultcan be regarded as highly unsatisfactory but should be viewed in the context that, firstly, the respective 18.2 learners were those mainly affected by non-completion (68\% compared to $11 \%$ of the 18.1 learners) and, secondly, 18.2 learners entirely made up the group of respondents who stated that they did not have an employer. Unsurprisingly, the two factors of 'completion' and 'involvement of an employer' also had a significant effect on the employability of the construction learners, as displayed in Table 6.
Further analysis was performed to reveal differences in terms of employability by NQF level. Figure 3 indicates that the NQF level of the learners significantly influenced their employability (the figure displays only NQF levels 1 to 3 , as NQF levels 4 and 5 had only one respondent). Indeed, the higher the NQF level, the higher the employability of the learners $(p<0.01)$. Given the need of the industry for skills, particularly at NQF levels 3 to 4 , this result was not surprising. What is interesting in this context is that this finding partly contradicted the results of the learnership baseline survey (Jennings, Everatt \& Smith, 2005, p. 47), in which NQF levels 1 to 3 had a higher level of employability (51\%) than NQF levels 4 to $5(19 \%)$. Consistent with the current study, Jennings et al. $(2005$, p. 47) and McGrath and Paterson (2007, p. 310) have reported that NQF levels 6 to 7 had a considerably higher level of employability (95\%) than all the lower levels. Unfortunately, the learnership baseline survey did not reveal the differences among the first three NQF levels, which would have allowed further analysis.

\section{DISCUSSION}

\section{Learnership satisfaction and system appropriateness}

As is to be expected in the context of the low involvement of the employers in the learnership system, there is strong evidence that the overall satisfaction of the providers (the workplace and institutions) with the system is very low. What is significant, however, is that the providers feel that their low level of satisfaction is no reason to consider the system inappropriate; in fact, the majority of the respondents regard the system as an appropriate means for developing artisans for the industry and criticisms expressed by the respondents are strongly related to issues of practical implementation rather than to the general concept of the system. Overall, the majority of the respondents furthermore perceive the learnerships as a training mode that gives them the opportunity to enhance skills in the industry and to empower employees. The structured, holistic form of the learning (combining both theory and prac tice) and the practical applicability of the training are the most striking features for the companies and training providers. In general, the providers, despite their dissatisfaction, therefore demonstrate a fairly high level of motivation and consequently intend to become or stay

TABLE 6

Differences in learner groups - construction learner results

\begin{tabular}{lccc}
\hline \multirow{2}{*}{ Characteristic } & \multicolumn{2}{c}{ Employed in construction } & \\
\cline { 2 - 3 } & Employed & Not employed & $p$ \\
\hline 18.1 (previously employed) & $82 \%(n=61)$ & $18 \%(n=13)$ & $<0.01^{*}$ \\
18.2 (previously unemployed) & $32 \%(n=18)$ & $68 \%(n=31)$ & \\
& & & \\
Completed learnership & $66 \%(n=71)$ & $34 \%(n=37)$ & $0.01^{*}$ \\
Not completed & $36 \%(n=8)$ & $64 \%(n=14)$ & \\
& & & \\
Training with employer & $77 \%(n=74)$ & $23 \%(n=22)$ & $<0.01^{*}$ \\
Training without employer & $15 \%(n=5)$ & $85 \%(n=29)$ & \\
\hline${ }^{*} p \leq 0.01$ & & & \\
& & &
\end{tabular}




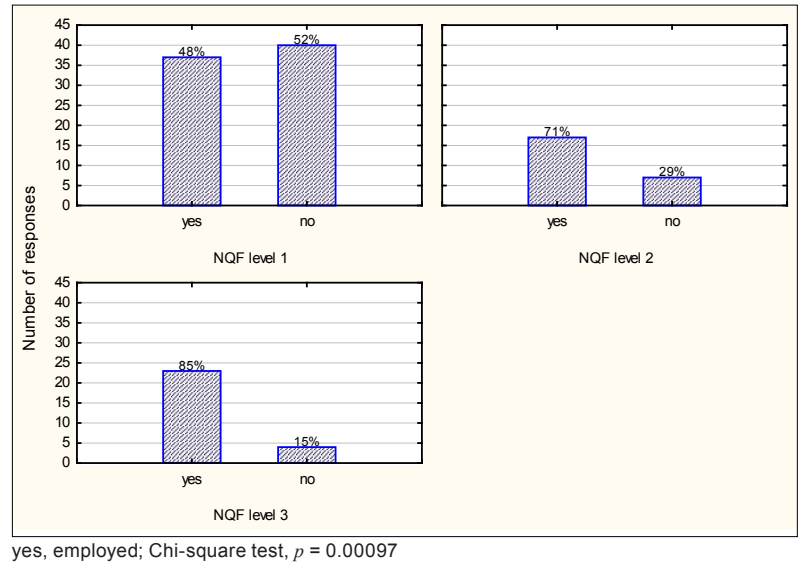

FIGURE 3

Employment status by NQF level

involved in the learnership system. This motivation, especially in the case of the employers, is clearly heightened by the skills shortage of approximately 7500 artisans per year across all the major trade categories (DoL, 2007), which was confirmed by the current study. The generally expressed motivation for the learnerships is, however, affected negatively by the fact that the providers, particularly the employers, do not feel adequately prepared for the learnerships.

\section{Learnership competence and processes}

Across the entire study, the companies demonstrated a tremendous lack of awareness and understanding of the learnerships and what they entail in terms of implementation. The institutional and workplace providers furthermore perceive the processes of the actual implementation of the system as highly bureaucratic, in some cases ineffective and certainly involving too much paperwork. The majority of the providers feel that they require more support from CETA in terms of actually implementing the learnerships (in other words learnership competence) and a simpler, more userfriendly structure of learnership processes; an interesting observation is that this support is requested from CETA. The level of learnership competence among the small and medium-sized employers was found to be significantly lower than that of the larger companies. The other results, however, do not vary significantly with the size of the companies and are neither positively nor negatively influenced by whether or not the companies are already involved in the learnerships. All the employers, independent of their size and involvement in learnership training, therefore demonstrate the same level of satisfaction with and motivation for the learnerships. Their perceptions of the learnership processes as well as the outcome of the system furthermore do not differ significantly. Notably, in terms of effectiveness (outcome), the system holds promise for the primary beneficiaries of the learnership system and consequently for the learners.

\section{Learner satisfaction}

The learners demonstrate a high level of overall satisfaction and generally appreciate the opportunity for skills development that they are given by the system. Primary inefficiencies as revealed by the learners are perceived to be in the financing of the training, as some learners could not complete their learnerships due to financial controversies between the provider and CETA, and in delays in the processing of their certificates upon qualification. Once again, it is positive to note that the learnerships are generally perceived by the learners to have a very positive impact on their employment and, moreover, on their income and career prospects.

\section{Learnership outcomes}

Across all the groups, there is positive evidence that the learnerships do achieve one of the most important outcomes, namely the employability of the learners. This study found that the system achieves a very high level of employment, with $61 \%$ of the responding learners being employed in construction. The level of employment does, however, vary significantly under the influence of certain factors (18.1 versus 18.2, completion and non-completion, the involvement or non-involvement of the employer in the training and NQF levels). As a result, 18.2 learners, who had completed their learnerships and had been trained with employer involvement (in other words who had not undergone pure, formal training programmes), had a higher chance of employment than those not having completed their learnerships (due to the discussed financial problems) and those having been trained without employer participation. In addition, employment level significantly increases with the NQF level of the acquired qualification. Despite the positive outcome in terms of employability, however, the system, in the opinion of the respondents, does not yet deliver a satisfactory level of applied competence and is consequently not effective in achieving the actual work readiness of learners. This result will certainly be required by the labour market in the long term. The respondents feel that more technical and practical competence needs to be trained for over a longer period of time if adequately skilled artisans are to be developed for the industry.

\section{Key learnership-programme challenges}

Overall, the following key challenges could be identified from the quantitative and qualitative findings of this study. These challenges were identified as being dominant across the different stakeholder groups:

- CETA support services and processes

- learnership content

- duration of artisan training

- recruitment and selection of learners

- availability of suitable learner candidates.

\section{CETA support services and processes}

Given the key role of CETA in the promotion and governance of the system in the sector, one of the major challenges observed is the lack of support given by CETA as well as its general services and applied processes. As perceived by the stakeholders, CETA is not yet delivering the support required by them, particularly in terms of the actual implementation of the learnerships (in other words practical guidance for employers and providers). Furthermore, the bureaucratic and/or ineffective administration (in, for example, the WSP, the portfolio of evidence and certification), including financial procedures, should be rectified urgently if the industry is to regain its trust in CETA and become involved on a broader basis. This challenge may, in part, be addressed by current legislative revisions through the Skills Development Amendment Act, Act No. 37 of 2008 (RSA, 2008). The newly established Quality Council for Trades and Occupations (QCTO) also takes over the currently performed quality-assurance function of the Education and Training Quality Assurance (ETQA) bodies from the SETAs and will therefore free capacity for delivering practical employer and provider support.

\section{Learnership content}

As criticised by the providers and key informants (from CETA and the leading industry associations and bodies), the learnership contents of the various NQF levels no longer meet industry requirements (whether partially or fully) and there is no consistent training process on HIV/Aids-related issues. For some critical trades, no learnerships exist whatsoever. An urgent analysis and revision of all learnership contents, with the involvement of the industry, are therefore strongly 
recommended. With the establishment of the QCTO, revised national occupational curricula will be developed, which will be based on needs identified by the industry and further developed with the involvement of Communities of Expert Practitioners (experts active in the industry and conducting the actual profession). A final, external assessment at national level will ensure that all learners acquire the same level of competence to qualify for their occupations.

\section{Duration of artisan training}

The duration of artisan training (18 months on average) is viewed as too short to develop qualified trades people (at NQF levels 3 to 4). The length of practical training at the actual workplace, in particular, is considered as insufficient. On average, the employers and providers recommend a total minimum training duration of between 24 months and 30 months. The newly developed occupational curricula will therefore need to consist of three compulsory components: a knowledge component, a practical-skills component and a work-experience component. All three components will have to be completed and passed as an entry requirement to final national assessment. This will ensure that the workplace is sufficiently covered in respect of future training. Furthermore, the industries, in developing their curricula, will set the standards for their length of training.

\section{Recruitment and selection of learners (particularly 18.2 learners)}

The stakeholders feel that the recruitment and selection processes of the learners (particularly the 18.2 learners) should be managed with care, as, otherwise, candidates may show low levels of interest in or aptitude for the industry and the success of the learnership is endangered right from the start, leading to high drop-out and failure rates during the course of the training. This challenge should be addressed by the employers themselves setting an adequate standard and selection procedure for the identification of their learners.

\section{Availability of suitable learner candidates}

Related to the relatively poor employer image of the construction industry, the recruitment of suitable learner candidates has been identified as an additional challenge. This image can be addressed only with a concerted effort among employers, providers and CETA. Training and career opportunities should be provided as a way to enhance the sector's image as an attractive employer in the long term.

Based on the identified key challenges, this study establishes a number of recommendations and therefore makes specific proposals to CETA regarding possible interventions in the system. Even though the study has concentrated particularly on the learnership system in the construction industry, some of the obstacles discussed in this paper could also be relevant to other sectors and could contribute arguments and ideas to the general implementation process of the learnership system at national-policy level. Accordingly, the identified challenges and suggested solutions have also been submitted to the Department of Labour and all other SETAs. As discussed, some key implementation areas, particularly industry-relevant curriculum design and the quality of learning outcome, will be addressed by current legislative revisions. The Skills Development Amendment Act, Act No. 37 of 2008 (RSA, 2008) will establish a new quality-assurance body, the QCTO, which will guide all training that is related to trades and occupations from a labour market-orientated perspective. The QCTO, as a single body, will replace the 23 ETQA bodies currently performing quality assurance and will therefore simplify the process of accreditation for providers and employers, which will need to interact with only one body.

Overall, this paper has not only identified key challenges relevant to the efficient and effective implementation of learnerships at national level but also established a base model for evaluating learnerships. Accordingly, it provides a practically tested tool for future learnership evaluations in all national sectors and is therefore highly relevant in the broader context of enhancing and improving skills development in South Africa. Future research in this area should focus on a close analysis of the potential causal relationships among the different factors included in the current learnership-evaluation framework and on the continuous improvement of the learnership system.

In addition, the developed evaluation model can not only be used in a learnership context but, as it follows a systems approach to training, should also be transferred to all training evaluations conducted in a complex multi-stakeholder environment. The concept of a stakeholder framework assists in identifying the key stakeholders of a system and in displaying the complex interactions among them. It therefore provides guidance for all evaluations that intend to involve the opinions of multiple stakeholders according to their assumed roles within the system.

\section{REFERENCES}

Aspinwall, K., Simkins, T, Wilkinson, J.F., \& McAuley, M.J. (1992). Managing evaluation in education. London: Routledge.

Babb, S. (2004). Learnerships in South Africa: Factors which help and hinder. Unpublished master's research report, Gordon Institute of Business Science, University of Pretoria, Pretoria, South Africa.

Babb, S., \& Meyer, T. (2005). Perspectives in learnerships. South African case studies. Randburg: Knowledge Resources.

Berger, M., \& Douglas, J. (2004, December). Initial teacher education Learnerships in South Africa: Lessons from the evaluation of the three-year pilot. Paper presented at the Third Conference of the African Evaluation Association, Cape Town, South Africa.

Bramley, P. (1991). Evaluating training effectiveness. Translating theory into practice. Berkshire: McGraw-Hill.

Bureau of Economic Research (BER). (2008). Quarterly analysis of building and construction activity - First Quarter 2008, 23(1). Stellenbosch: BER.

Campbell, P.C. (1998). Training course/program evaluation: Principles and practices. Journal of European Industrial Training, 22(8), 323-344.

Centre for Development and Enterprise (CDE). (2007). The South African skills crisis. A report from the corporate coalface. Johannesburg: CDE.

CETA. (2007). Sector skills plan 2007/08. Midrand: CETA.

CIDB. (2004). SA construction industry. Status report - 2004. Synthesis review on the South African construction industry and its development. Pretoria: CIDB.

CIDB. (2006). Demand for skills: An analysis of the proposed infrastructure spending programme. Pretoria: CIDB.

CIDB. (2007a). Skills infrastructure delivery in South Africa: The challenge of restoring the skills pipeline. Pretoria: CIDB.

CIDB. (2007b). 5 year review of the Construction Industry Development Board, February 2007. Pretoria: CIDB.

Creswell, J.W. (2007). Qualitative inquiry and research design: Choosing among five approaches. (2nd edn.). Thousand Oaks: Sage.

Davies, T.-A., \& Farquharson, F. (2004). The learnership model of workplace training and its effective management: Lessons learnt from a South African case study. Journal of Vocational Education and Training, 56(2), 181-203.

De Jager, S., Hattingh, S., \& Hüster, E. (2002). How to implement a learnership. A guide for employers and training providers. The learnership development series, book 4. Pretoria: German Technical Co-operation. 
Department of Labour (DoL). (2007). JIPSA progress report, March 2007. Retrieved May 15, 2007, from http://www.info. gov.za/asgisa/

Dillman, D.A., Tortora, R.D., Conradt, J., \& Bowker, D (1998, August). Influence of plain vs. fancy design on response rates for web surveys. Paper presented at Joint Statistical Meetings, Dallas. Retrieved June 20, 2007, from http://survey.sesrc. wsu.edu/dillman/papers/ asa98ppr.pdf.

Edney, P.J. (1972). A systems analysis of training. New York: Pitman Publishing.

Erasmus, B.J., \& Van Dyk, P.S. (1996). Training management - A practical approach. Johannesburg: International Thomson Publishing.

Fester, R.R. (2006). Academic staff's perceptions of learnership programme delivery at a further education and training institution. Unpublished mini-dissertation, University of Johannesburg, South Africa.

Goldmann, T. (2003). Organizing in the informal economy: A case study of the building industry in South Africa. Seed working paper no. 38. Geneva: International Labour Office.

Heitmann, W. (2004). The action oriented learning approach for promoting occupational performance and employability. Skills development research series. Pretoria: German Technical Co-operation.

Jennings, R., Everatt, D., \& Smith, M.J. (2005). Baseline evaluation of the learnership programme. In Department of Labour (DoL) (Ed.), Labour Market Review (pp. 41-50). Pretoria: Department of Labour.

Kerlinger,F.N., \& Lee,H.B.(2000). Foundations ofbehavioral research. (4th edn.). Orlando: Harcourt College.

Kruss, G. (2004). The Western Cape micro-economic development strategy project. Towards a multi-level skills strategy in the Western Cape. Final second-phase paper. Cape Town: HSRC Press.

Madaus, G.F., Airasian, P.W., \& Kellaghan, T. (1980). School effectiveness. A reassessment of the evidence. New York: McGraw Hill.

McGrath, S., \& Martins, J. (2005). The VSME component of the national skills survey. In S. McGrath (Ed.), Skills development in very small and micro enterprises, (pp. 31-52). Cape Town: HSRC Press.

McGrath, S., \& Paterson. (2007). Enterprise training. In A. Kraak \& K. Press (Eds.), HRD review 2008. Education, employment and skills in South Africa, (pp. 300-321). Cape Town: HSRC Press.

Meyer, M., \& Bushney, M. (2007). 5th annual ASTD state of the South African training industry report 2007. Randburg: Knowres Publishing.
Mummenthey, C. (2008). Implementing efficient and effective learnerships in the construction industry. A study on the learnership system in the building and civil sector of the Western Cape. Unpublished master's thesis, Stellenbosch University, South Africa.

Nankani, G. (2006, March 12). African countries focus on infrastructure gaps. The Africa Report, p. 79.

Nielsen, S.P., \& Visser, K. (1997). Quality debate in initial vocational education. School-based quality measures at intermediate level: A Danish-Dutch comparison. Thessaloniki: CEDEFOP. Retrieved May 19, 2007, from http://www.cedefop.europa. eu/index.asp?section $=5 \& \mathrm{sub}=5$.

Ntinga. (2002). Final report: Sub-sector analysis and BDS market assessment of the South African construction sector. Braamfontein: World Education Ntinga.

Patrick, J. (1992). Training: Research and practice. London: Academic Press.

Punch, K.F. (1998). Introduction to social research. Quantitative and qualitative approaches. London: Sage.

Republic of South Africa. (1998). Skills Development Act No. 97 of 1998. Government Gazette, 2 (No. 19420).

Republic of South Africa. (1999). Skills Development Levies Act No. 9 of 1999. Government Gazette. (No. 406).

Republic of South Africa. (2008). Skills Development Amendment Act No. 37 of 2008. Government Gazette. (No. 841).

Rubin, A., \& Babbie, E. (2007). Essential research methods for social work. Belmont: Thomson Brooks/Cole.

Smith, M.J., Jennings, R., \& Solanki, G. (2005). Perspectives on learnerships: A critique of South Africa's transformation of apprenticeships. Journal of Vocational Education and Training, 57(4), 537-561.

STATS SA. (2008). Gross domestic product. Press statement. Retrieved March 03, 2008, from http://www.statssa.gov.za/ keyindicators/GDP/PressStatement.pdf.

Thejane, T. (2007). CEO's update - Big challenges ahead for CETA. Columns Jan/Feb 2007. Midrand: CETA.

Van Selm, M., \& Jankowski, N.W. (2006). Conducting online surveys. Quality \& Quantity, 40, 435-456.

Wolhuter, C.C. (2003). The envisaged dual system of vocational education and training in South Africa: Assessing the potential thereof from a comparative perspective. South African Journal of Education, 23(2), 145-151. 